\title{
An Application of the Theory of Planned Behavior and Uses and Gratifications Theory to Food-Related Photo-Sharing on Social Media
}

\author{
Sarah E. Pember ${ }^{1}$, Xueying Zhang ${ }^{2}$, Kim Baker ${ }^{3}$, and Kim Bissell ${ }^{4}$ \\ ${ }^{1}$ University of Wisconsin-La Crosse, Department of Health Education and Health Promotion \\ ${ }^{2}$ Department of Communication Studies, Kent State University \\ ${ }^{3}$ Alabama State University \\ ${ }^{4}$ College of Communication \& Information Sciences, University of Alabama
}

\begin{abstract}
Background and Purpose: Food-related photos are prolific on social media, but little is known about user motivations for sharing food photos. While food brands have begun to strategically utilize social media to target consumers and their eating behaviors, health promotion practitioners have made less concerted efforts in this area, perhaps because there is little research into the motivations and rewards for sharing food-related photos online. This study applies the Theory of Planned Behavior (TPB) and Uses and Gratifications ( $\mathrm{U} \& \mathrm{G}$ ) Theory to food-related social media photo sharing, thus, laying groundwork for future investigations of image-based nutrition education messaging. Methods: An online survey designed within the framework of the TPB and U\&G was administered to both a community population and that of a large, Southeastern university $(N=478)$. Results: Attitudes were generally positive toward the behavior, and, within the TPB, the only significant predictor of intention to share food-related photos on social media. Primary motives for posting were entertainment and personal utility, while those for viewing others' posts were entertainment and information-seeking. Conclusions: Food-photo sharing is a positive, socially normative behavior through which users gather information in an entertaining way, making social media prime tools for communicating healthy eating image-based messages.
\end{abstract}

(C) 2018 Californian Journal of Health Promotion. All rights reserved.

Keywords: Theory of Planned Behavior, Uses and Gratifications Theory, social media, health communication, health promotion, nutrition education

\section{Introduction}

Social media use has become commonplace among adults in the United States. According to the Pew Internet Research project (2014), 74\% of all adult internet users are active on social media networking sites. Sharing food-related photos through social media has also become common. One study showed $37.1 \%$ of college students upload photos of dining experiences on social media outlets with moderate to high frequency (Bilgihan, Peng, \& Kandampully, 2014). Another study found that males posted an average of 86.7 pictures relating to food and drink on Pinterest, while females averaged 138.4 "pins," or posts, relating to food and drink (You, Bhatia, Sun, \& Luo, 2014). The first content analysis of Instagram found a slightly more than $10 \%$ of photos were food-related $(\mathrm{Hu}$, Manikonda, \& Kambhampati, 2014). The phenomenon of posting food photos on Instagram now even has name: "foodstagramming" (Ginsberg, 2015).

While food brands have begun to strategically utilize social media to target consumers and their eating behaviors (Ginsberg, 2015), health educators have made less concerted efforts in understanding motivations for these attitudes and behaviors. This lack of research may be, in part, because there are no peer-reviewed reports of the motivations for posting and sharing food photos via social media applications by individuals nor the intrinsic or extrinsic rewards they receive for this behavior.

Social norms are well-established influences over how we eat, which, in turn, can affect food 
choices and food consumption (Higgs, 2016; Pelletier, Graham, \& Laska, 2014; Pliner \& Mann, 2004; Robinson, Thomas, Aveyard, \& Higgs, 2014;). Because they may function as a salient social network, social media photosharing applications potentially have the power to create or influence normative perceptions. College students have said they are influenced by what they see others post on social media, both regarding exercise- and food-related content (Vaterlaus, Patten, Roche, \& Young, 2015), and it has been found that repeatedly viewing photographs of certain types of food can actually decrease your appetite for those foods (Larson, Redden, \& Elder, 2014), leading to what has been touted in popular media as "The Instagram Diet." If using social media is normative and taking photos of food is becoming a more common practice, Instagram and similar sites may have the power to set social norms for eating behavior and subsequently influence the healthy eating intentions of people who use the applications.

New media, including the explosive growth of smartphone-based mobile technology, "have enormous potential to revolutionize health education" (Bernhardt, Chaney, Chaney, \& Hall, 2013). Social networking applications may act as "a powerful tool for self-realization" (Hingle et al., 2013), with strong potential for affecting behavior change because of their abilities to provide immediate, relevant, and personalized information, and to offer real-time interactions among peers and counselors (Bernhardt et al., 2013; Hingle et al., 2013). However, theoretical approaches to behavior change in current mobile applications are currently lacking (West et al., 2011; West et al. 2013) but are needed in the development of new apps and the design of interventions utilizing mobile technology (Young et al., 2014). The purpose of this study was to understand social media food photosharing acts within the framework of the Theory of Planned Behavior (TPB), which has posited that attitudes, perceived norms, and perceived behavioral control influence and guide behavioral intentions (Azjen, 1991). Additionally, this study drew from Uses and Gratifications (U\&G) Theory of Communication (Ruggiero, 2000), which is applicable for exploring the motivations for engaging with media, thus, establishing a better understanding of food-related photo sharing uses, gratifications, and motivations on social media. The findings may ultimately contribute to future theory-based studies and promotions of healthy eating via these communication channels, while also laying groundwork for future investigations of image-based nutrition research, education, and communications on social media.

Based on the previous studies, the current study proposed the following hypotheses:

H1: Social media users' intention to post foodrelated photos is predicted by factors in TPB constructs, including (a) injunctive norm, (b) descriptive norm, (c) attitude toward posting and (d) perceived behavioral control

$\mathrm{H} 2$ : Social media users' intention to post foodrelated photos is predicted by factors in TPB constructs, including (a) injunctive norm, (b) descriptive norm, (c) attitude toward posting and (d) perceived behavioral control

\section{Methods}

Following Institutional Review Board approval from the research institution, the survey was administered to both community and university populations $(N=478)$, through internet-based snowball sampling and the college's student pool of study participants.

Independent variables related to TPB constructs were measured with 7-point Likert-scales. Questions relating to each of the TPB constructs were created based on guidelines proposed by Fishbein and Azjen (2010) for designing a reasoned action questionnaire in measuring health intentions and behaviors. Specifically, attitudes were measured with a semanticdifferential, asking respondents to complete the phrase "Posting food-related photos on social media is..." and then providing selection sets of descriptors of bad/good, meaningless/worthwhile, boring/fun (reliability $\alpha=.81)$. The same question was asked in assessing attitudes toward looking at other people's food-related photos. Perceived behavioral control was measured with a response to the statement "I am confident that I 
could post food-related photos on social media if I wanted to do so." Injunctive norms were measured by asking participants to rate the approval of three separate referent groupsfamily members, friends, and social media followers (reliability $\alpha=.89$ ). This was combined with a descriptive norm measure ("Most people like me post food-related photos on social media") for an overall subjective norm score.

Another set of independent variables related to uses and gratifications were modeled on previous studies of the uses and gratifications of the Internet and social media sites (Papacharissi \& Rubin, 2000; Parker \& Plank, 2000; Raacke \& Bonds-Raacke, 2008), and focused on the U \& $G$ categories of entertainment, information seeking, personal utility, altruism, and social interaction. All these motivation variables were measured by asking participants whether they use social media for the reason of engaging with related activities.

As to the dependent variable, the survey asked respondents about their intentions to share foodrelated photos on social media using a 7-point Likert scale. The survey also asked respondents to report their average number of photos posted on social media per day and per week.

Regression analyses were conducted between all TPB constructs and intention to post (i.e. "I intend to post 1 food-related photo on social media today"), and reported behavior (i.e. "On average, how many food-related photos do you post each day?"). Since motivations of social media use were measured with a binary scale, independent $t$-tests were used to evaluate the effects of individual $U$ \& $G$ motives with intentions to share.

\section{Results}

Participants were predominantly female (78.19\%), White $(85.22 \%)$, full-time students $(86.1 \%)$. Ages ranged from 18 to 72 , with the average of $22.71(S D=8.58)$. The majority of respondents $(58.15 \%)$ reported sharing food photos on social media; an even greater proportion $(87.75 \%)$ reported viewing others' food-related posts. Of those who shared food photos, $21.84 \%$ reported that they post more healthy foods than unhealthy items, with $32.57 \%$ reporting equal amounts of unhealthy and healthy foods. Nearly one-third of users indicated not spending any time thinking about the healthfulness of their food posts. Table 1 show demographic data and overall social media application use.

Table 1

Demographic Characteristics of the Sample

\begin{tabular}{lrr}
\hline & $\mathrm{n}$ & $\%$ \\
\hline Gender & & \\
Male & 98 & 21.3 \\
Female & 259 & 78.0 \\
Transgender & 0.4 \\
No answer & 1 & 0.2 \\
Ethnicity & & \\
African-American & 40 & 21.3 \\
White & 390 & 85.3 \\
American Indian or & 2 & 0.4 \\
Alaskan Native & & \\
Native Hawaiian & 1 & 0.2 \\
Other & 3 & 3.1 \\
College Student Status & & \\
Yes & 397 & 86.1 \\
No & 64 & 13.9 \\
Social Media Use & & \\
Facebook & 434 & 91.6 \\
Twitter & 343 & 72.4 \\
Instagram & 415 & 87.6 \\
Snapchat & 381 & 80.4 \\
Tumbler & 137 & 28.9 \\
Pinterest & 263 & 55.5 \\
Whatsapp & 36 & 7.6 \\
GroupMe & 304 & 64.1 \\
Google Circles & 23 & 4.9 \\
Others & 22 & 4.6 \\
\hline
\end{tabular}

The first set of hypotheses proposed that individuals' intentions to post food-related photos on social media is predicted by TPB constructs, including injunctive norm, descriptive norm, attitudes toward posting, and perceived behavioral control. As shown by Table 2, the mean attitude score was $3.02(S D=$ 
1.36) on a 7-point scale, with a lower score indicating more favorable attitudes. The mean perceived injunctive norm was $5.54(S D=1.33)$ on the 7-point scale, and the mean perceived descriptive norm was $5.39(S D=1.451)$. The mean perceived behavioral control was $6.26(S D$ $=1.27)$. The regression coefficients suggested that only attitudes toward posting served as a significant predictor. $(\beta=.22, p<.01)$. The regression results also indicated that attitudes toward posting as a significant predictor of numbers posted per day $(\beta=.13, p<.05)$. Therefore, H1a, H2a, H1b, H2b, H1d and H2d were rejected; whereas, $\mathrm{H} 1 \mathrm{c}$ and $\mathrm{H} 2 \mathrm{c}$ were supported.

The primary uses and gratifications of posting food-related photos are entertainment and personal utility. Almost all participants (93.6\%) reported posting photos "to share an experience" and $72.1 \%$ reported wanting "to show off food they made". The other top five reported motives for sharing food-related posts were entertainment-related, with $88.9 \%$ reporting that they post "because they enjoy it"; $80.1 \%$ "because it's fun"; and $73.7 \%$ "because it's entertaining." Just over half of respondents $(51.4 \%)$ also reported posting "to help promote a restaurant." Uses and gratifications for viewing other people's food posts fell predominantly into the categories of entertainment and information seeking. A majority of the users reported looking at other people's photos "to find new recipes" (77.1\%); "to see what others eat" $(79.3 \%)$; "to learn about new brands or products" $(69.8 \%)$; "to learn about new foods" $(82.4 \%)$; "to be inspired" (75.5\%); and "to compare their food with others' food" (55.4\%).

Our RQ asked if the motives of posting influenced intentions for posting and the number of photos posted. A series of independent $t$-tests were conducted to test if motives of social media use were significantly related to individuals' intentions to share food-related photos. As suggested by Table2-1, two motives significantly influenced users' intentions to share food-related photos: because it is entertaining $(t=3.74, p<0.01)$, and to show off food they made $(t=1.90, p<0.05)$. Two motives significantly influenced the reported average number of posts per day: because it's entertaining $(t=2.01, p<.05)$ and because it's fun $(t=2.42, p<.05$, ) (Table 2-2). These motives because it's entertaining $(t=2.31, p<$ $.05)$ and because it's fun $(t=2.62, p<.01$, $)$ also significantly influenced the reported average number of posts per week (Table 2-3).

Table 2

Regression of TPB Factors on Intentions to Post Food-related Photos on Social Media (N=252)

\begin{tabular}{lrrrrrrr}
\hline & \multicolumn{2}{c}{$\begin{array}{l}\text { Intention to } \\
\text { share }\end{array}$} & \multicolumn{2}{c}{$\begin{array}{l}\text { \# Photos } \\
\text { posted }\end{array}$} & \multicolumn{3}{c}{$\begin{array}{l}\text { \# Photos } \\
\text { posted/week }\end{array}$} \\
\hline & $M(S D)$ & $\beta$ & $p$ & $\beta$ & $p$ & $\beta$ & $p$ \\
\hline Injunctive norms & $5.54(1.33)$ & .11 & .21 & .05 & .61 & .06 & .47 \\
$\begin{array}{l}\text { Descriptive norms } \\
\text { Attitudes toward }\end{array}$ & $5.39(1.45)$ & .14 & .11 & .12 & .17 & .08 & .33 \\
posting & $3.02(1.36)$ & .22 & $<.01$ & .13 & $<.05$ & -.10 & .12 \\
$\begin{array}{l}\text { Perceived } \\
\text { behavioral control }\end{array}$ & $6.29(1.27)$ & .07 & .34 & .01 & .92 & -.01 & .92 \\
\hline
\end{tabular}

\section{Discussion}

\section{Summary of the Findings}

The finding that attitude was the strongest predictor of intention aligns with previous studies of the use of the Theory of Planned
Behavior for health-related behavioral intentions, including nutrition-related behaviors in youth (Hagger et al., 2016), alcohol consumption (Cooke et al., 2016), and healthy eating during parenthood transitions (Bassett- 
Gunter et al., 2013). Research on the effects of attitudes have long been cited as the strongest predictor of intentions over subjective norms; however, it has been argued that attitudes may actually be a byproduct of subjective norms, in that norms may influence attitudes, which then more explicitly influence intentions (Terry \& Hogg, 1996). Kim et al., (2016) did recently find in a closely related study that subjective norms for selfie-posting on social media was a slightly stronger predictor of intentions than attitudes; however, both variables were significant. Additionally, attitudes and normative beliefs may not be mutually exclusive, and attitudes may only find behavioral expression within supportive normative environments. Given the generally high perceptions of approval by family, friends, and social media followers for posting photos online and the generally positive attitudes toward the behaviors, it may be that the perceptions of normative support are increasing attitudes toward sharing photos online. Because the designation of who is considered a normative reference may change based on the context of the behavior (Louis, Davies, Smith, \& Terry, 2007), it is also worth considering that posting photos online may be an activity that is more highly regarded when thought about in the context of an online social network instead of the "real world." Regardless of how attitudes and subjective norms may or may not interact in relation to social media behavioral intentions, this is an important finding, as sharing healthrelated information between social groups may improve the health and nutrition-related behaviors of families and social contacts (Sheldon, 2012). Capitalizing on this desire to share may increase the abilities of health educators to spread positive, image-based nutrition-related messages to a larger community through social media channels, especially in the college-aged population that composed the majority of this study's population.

Previous studies have shown Facebook to be an effective method of recruitment for difficult to reach populations in nutrition education evaluation (Lohse \& Wambolt, 2013). However, social media advertising and promotion with the greatest reach, such as paid Facebook or Google advertisements, did not achieve as many inquiries as targeted letters during recruitment of young adults for a weight gain prevention intervention (Partridge et al., 2015). Perhaps the future of nutrition communication lies in training of digital community health workers (CHWs), who, like traditional CHWs, are trusted members of specific communities trained to share health-based information with those around them (Witmer et al. 1995), and have the potential to be valuable assets for public health intervention both in the U.S. and abroad (Balcazar et al., 2011; Perry, Zulliger, \& Rogers, 2014). However, instead of working to promote health in physical communities, these digital CHWs could work within their online photosharing social networks to promote photo-based healthy eating and nutrition education.

\section{Limitations}

As with any study utilizing TPB, it is important to note that intentions do not always manifest in actual behavior. Although questions were asked regarding self-report of average behavior, this study was cross-sectional in design, and, while still valuable, it cannot offer the insights of a longitudinal study design. Additionally, this sample was predominantly White, female college students, and it is difficult to know if the findings are reflective of that particular population as being the most likely to participate in food-related photo-sharing on social media or is a result of sampling bias. To better understand and apply this research to the social media landscape as a whole, it is important to replicate this work with a larger community sample, with more diversity of age, gender, and racial and ethnic identity.

\section{Implications of the Study}

Despite those limitations, this study is novel in its combined use of both health behavior and communication theory to better understand intentions and behavior related to food-photo sharing online. Combining efforts from the fields of health behavior and communication is more likely to result in effective tailored messaging for target populations (Fishbein \& Cappella, 2006). Although a majority of the study sample were young adults, this sample reflects national data as this is also the age group that continues to be the most likely to use social 
media in both the U.S. (Greenwood, Perrin \& Duggan, 2016; Perrin, 2015) and Great Britain (Mellon \& Prosser, 2017). Overall results do suggest that trends for this behavior to be normalized in female adults as well, who are the second-largest population of social media users in the U.S. (Greenwood, Perrin, \& Duggan, 2016).

Food-photo sharing is a positive, socially normative behavior through which users gather information in an entertaining way, making social media prime tools for communicating healthy eating image-based messages. Because many people are willing and able to post food photos online, the potential for promoting healthy eating through digital community health workers is worthy of investigation, especially in a population of young adult females, who represent a majority of participants in this study. Future research is needed to better understand the food photo-sharing of this and other populations, and to develop and test tailored messages based upon the most popular uses and gratifications among different subgroups.

\section{References}

Ajzen, I. (1991). The theory of planned behavior. Organizational Behavior and Human Decision Processes, 50(2), 179-211.

Balcazar, H., Rosenthal, E., Brownstein, J., Rush, C., Matos, S., \& Hernandez, L. (2011). Community health workers can be a public health force for change in the United States: Three actions for a new paradigm. American Journal of Public Health, 101(12), 2199-203.

Bassett-Gunter, R. L., Levy-Milne, R., Naylor, P. J., Downs, D. S., Benoit, C., Warburton, D. E., Blanchard, C.M., \& Rhodes, R. E. (2013). Oh baby! Motivation for healthy eating during parenthood transitions: A longitudinal examination with a theory of planned behavior perspective. International Journal of Behavioral Nutrition and Physical Activity, 10 (88).

Bernhardt, J. M., Chaney, J. D., Chaney, B. H., \& Hall, A. K. (2013). New media for health education: A revolution in progress. Health Education \& Behavior, 40(2), 129-132.

Bilgihan, A., Peng, C., \& Kandampully, J. (2014). Generation Y's dining information seeking and sharing behavior on social networking sites: An exploratory study. International Journal of Contemporary Hospitality Management, 26(3), 349-366.

Cooke, R., Dahdah, M., Norman, P., \& French, D. P. (2016). How well does the theory of planned behaviour predict alcohol consumption? A systematic review and meta-analysis. Health Psychology Review, 10(2), 148-167.

Duggan, M., \& Smith, A. (2013). Social media update 2013. Pew Research Center. Retrieved from http://www.pewinternet.org/2013/12/30/social-media-update-2013/

Fishbein, M., \& Azjen, I. (2010). Predicting and changing behavior: The reasoned action approach. New York: Psychology Press

Fishbein, M., \& Cappella, J. N. (2006). The role of theory in developing effective health communications. Journal of Communication, 56(s1), S1-S17.

Ginsberg, K. (2015). Instabranding: Shaping the personalities of the top food brands on instagram. The Elon Journal of Undergraduate Research in Communications, 6(1), 78-91.

Greenwood, S., Perrin, A., \& Duggan, M. (2016). Demographics of social media users in 2016. Pew Research Center. Retrieved from http://www.pewinternet.org/2016/11/11/social-media-update2016/

Lohse, B., \& Wamboldt, P. (2013). Purposive Facebook recruitment endows cost-effective nutrition education program evaluation. Journal of Medical Internet Research Research Protocols, 2(2), e27.

Hagger, M. S., Chan, D. K., Protogerou, C., \& Chatzisarantis, N. L. (2016). Using meta-analytic path analysis to test theoretical predictions in health behavior: An illustration based on meta-analyses of the theory of planned behavior. Preventive Medicine, 89, 154-161.

Higgs, S. (2015). Social norms and their influence on eating behaviours. Appetite, 86, 38-44. 
Hingle, M., Nichter, M., Medeiros, M., \& Grace, S. (2013). Texting for health: The use of participatory methods to develop healthy lifestyle messages for teens. Journal of Nutrition Education and Behavior, 45(1), 12-19.

Hu, Y., Manikonda, L., \& Kambhampati, S. (2014). What we instagram: A first analysis of instagram photo content and user types. Proceedings of International Conference on the Web and Social Media (ICWSM). Association for the Advancement of Artificial Intelligence (AAAI)I.

Kim, E., Lee, J. A., Sung, Y., \& Choi, S. M. (2016). Predicting selfie-posting behavior on social networking sites: An extension of theory of planned behavior. Computers in Human Behavior, 62, 116-123.

Larson, J., Redden, J. P., \& Elder, R. (2013). Satiation from sensory simulation: Evaluating foods decreases enjoyment of similar foods. Journal of Consumer Psychology, 24(2), 188-194.

Louis, W., Davies, S., Smith, J., \& Terry, D. (2007). Pizza and pop and the student identity: The role of referent group norms in healthy and unhealthy eating. The Journal of Social Psychology, 147(1), 57-74.

Mellon, J., \& Prosser, C. (2017). Twitter and Facebook are not representative of the general population: Political attitudes and demographics of social media users. Research and Politics, 4(3), 1-9.

Papacharissi, Z., \& Rubin, A. M. (2000). Predictors of Internet use. Journal of Broadcasting \& Electronic Media, 44(2), 175-196.

Parker, B. J., \& Plank, R. E. (2000). A uses and gratifications perspective on the Internet as a new information source. American Business Review, 18(2), 43.

Partridge, S. R., Balestracci, K., Wong, A. T., Hebden, L., McGeechan, K., Denney-Wilson, E., Harris, M.F., Phongsavan, P., Bauman, A., \& Allman-Farinelli, M. (2015). Effective strategies to recruit young adults into the TXT2BFiT mHealth randomized controlled trial for weight gain prevention. Journal of Medical Internet Research Research Protocols, 4(2), e66.

Pelletier, J. E., Graham, D. J., \& Laska, M. N. (2014). Social norms and dietary behaviors among young adults. American Journal of Health Behavior, 38(1), 144-152.

Perrin, A. (2015). Social media usage: 2005-2015. Pew Research Center. Retrieved from http://www.pewinternet.org/2015/10/08/social-networking-usage-2005-2015/

Perry, H. B., Zulliger, R., \& Rogers, M. M. (2014). Community health workers in low-, middle-, and high-income countries: An overview of their history, recent evolution, and current effectiveness. Annual Review of Public Health, 35, 399-421.

Pliner, P., \& Mann, N. (2004). Influence of social norms and palatability on amount consumed and food choice. Appetite, 42(2), 227-237.

Raacke, J., \& Bonds-Raacke, J. (2008). MySpace and Facebook: Applying the uses and gratifications theory to exploring friend-networking sites. Cyberpsychology \& behavior, 11(2), 169-174.

Robinson, E., Thomas, J., Aveyard, P., \& Higgs, S. (2014). What everyone else is eating: A systematic review and meta-analysis of the effect of informational eating norms on eating behavior. Journal of the Academy of Nutrition and Dietetics, 114(3), 414-429.

Ruggiero, T. E. (2000). Uses and gratifications theory in the 21st century. Mass Communication \& Society, 3(1), 3-37.

Sheldon, L. (2012). Nutrition information sharing activities of community college students. Journal of Nutrition Education and Behavior, 44(4), S30.

Terry, D. J., \& Hogg, M. A. (1996). Group norms and the attitude-behavior relationship: A role for group identification. Personality and Social Psychology Bulletin, 22(8), 776-793.

West, J. H., Hall, P. C., Hanson, C. L., Barnes, M. D., Giraud-Carrier, C., \& Barrett, J. (2011). There's an app for that: content analysis of paid health and fitness apps. Journal of Medical Internet Research, 14(3), e72-e72.

West, J. H., Hall, P. C., Arredondo, V., Berrett, B., Guerra, B., \& Farrell, J. (2013). Health behavior theories in diet apps. Journal of Consumer Health on the Internet, 17(1), 10-24. 
Witmer, A., Seifer, S. D., Finocchio, L., Leslie, J., \& O'Neil, E. H. (1995). Community health workers: Integral members of the health care work force. American Journal of Public Health, 85(8_Pt_1), 1055-1058.

Vaterlaus, J. M., Patten, E. V., Roche, C., \& Young, J. A. (2015). \# Gettinghealthy: The perceived influence of social media on young adult health behaviors. Computers in Human Behavior, 45, 151-157.

You, Q., Bhatia, S., Sun, T., \& Luo, J. (2014, December). The eyes of the beholder: Gender prediction using images posted in Online Social Networks. In 2014 IEEE International Conference on Data Mining Workshop (pp. 1026-1030). IEEE.

Young, S. D., Holloway, I. W., \& Swendeman, D. (2014). Incorporating guidelines for use of mobile technologies in health research and practice. International Health, ihu019.

Author Information

Sarah E. Pember, Ph.D. (corresponding author)

University of Wisconsin-La Crosse

200 Mitchell Hall

La Crosse, WI 54601

(608) 785-6788

spember@uwlax.edu 